\title{
Ulnar Neuropraxia after Cath Procedure
}

\author{
Morgan Nelson, $M D^{1^{*}}$, Anesh P Rugnath, $M D^{2}$ and Michelle Sheth, $M D^{3}$ \\ ${ }^{1}$ Current Anesthesiology Residents, University of Mississippi Medical Center, USA \\ ${ }^{2}$ Assistant Professor, Department of Anesthesiology, University of MS Medical Center, USA \\ ${ }^{3}$ SOM-Anesthesiology, University of Mississippi Medical Center, USA
}

\section{Case Presentation}

18-year-old male (132 kg, BMI 40) with a past medical history of Wolf Parkinson White Syndrome presented for an EP study and ablation. The procedure, which was uncomplicated but prolonged, lasted eight hours. His large mid torso was wider than the table width. His arms hung off of the bedframe and were secured and tucked using egg crate and plastic arm boards. The interventional cardiologist had to lean inwards on the right side to access the cannulas in the groin to do the procedure, often for long periods. There was a clear indentation on the patient's arm where the plastic arm board was placed and pressure placed by the cardiologist inadvertently depicted in Figure 1. After the procedure, the patient was taken to the PACU where he became inconsolable, screaming that his arm was broken. He reported "pins and needles" sensations and was unable to move his arm. X-ray revealed no fracture and neurology was consulted. Per neurology, the pain and paresthesias resulted from an ulnar nerve neuropraxia due to pressure. They recommended no interventions, supportive care with warmth, NSAIDS, and continued movement of the extremity. He was discharged the next day but only regained full strength and sensation three months after the insulting event.

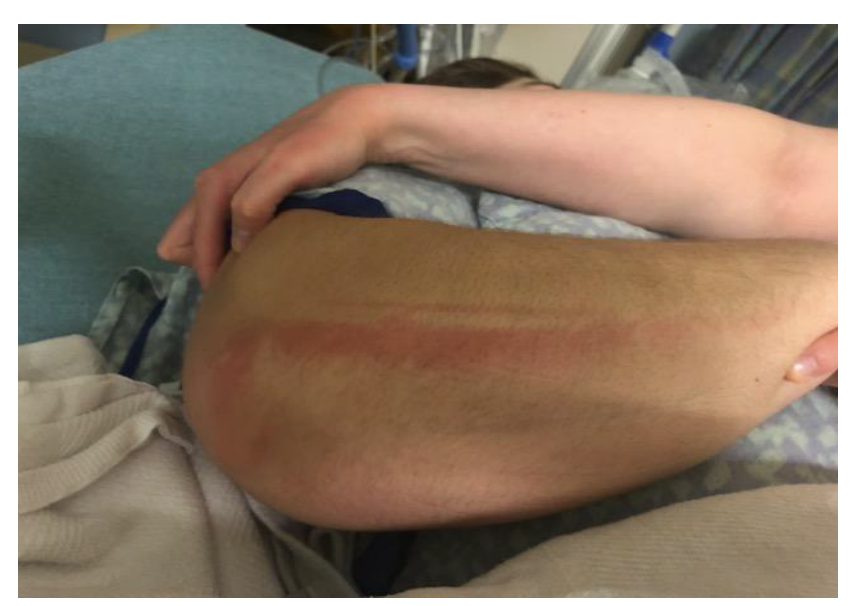

Figure 1: Ulnar nerve neuropraxia.

\section{Discussion}

"Surgically-Induced Neuropathic Pain (SNPP) can lead to persistent pain in $10-50 \%$ of individuals after common operations. latrogenic neuropathic pain is probably the most important cause of long term post-surgical pain [1]. Post-surgical neuropathies may result from direct surgical insult such as transection, contusion, or stretching by tissue manipulation. They may also result from positioning and external pressure. Although the arms were padded and tucked which are common preventative maneuvers, this did not prevent the pressure injury from the cardiologist's medial downward pressure as he leaned over to access the groins. The ulnar neuropraxia is presumed to be caused by the edge of the bed pinching the medial elbow as he leaned inwards. "Genetic factors should be evaluated as since only a proportion of intra-operative nerve damage develops into chronic pain" [2]. This case report emphasizes the need to be vigilant not only with positioning and padding before surgical procedure but also be vigilant as to the possibility of nerve damage from external pressure.

\section{References}

1. Borsook D, Kussman BD, George E, et al. (2013) Surgically induced neuropathic pain (SNPP): Understanding the perioperative process. Ann Surg 257: 403-412.

2. Kehlet H (2006) Persistant postsurgical pain: Risk factors and prevention. Lancet 367: 1618-1625.

\footnotetext{
*Corresponding author: Morgan Nelson, MD, Current Anesthesiology Residents, University of Mississippi Medical Center, USA Accepted: February 29, 2020

Published online: March 02, 2020

Citation: Nelson M, Rugnath AP, Sheth M (2020) Ulnar Neuropraxia after Cath Procedure. J Clin Anesth Pain Manag 4(1):96
}

Copyright: (c) 2020 Nelson M, et al. This is an open-access article distributed under the terms of the Creative Commons Attribution License, which permits unrestricted use, distribution, and reproduction in any medium, provided the original author and source are credited. 